\title{
Efficiency of electrochemical extraction of chlorides in fly ash concrete using carbon fibre mesh anode
}

\author{
Jiyue $\mathrm{Hu}^{\mathrm{a}}$, Shan $\mathrm{Li}^{\mathrm{a}, *}$, Yiyan Lu ${ }^{\mathrm{a}}$, Hongyuan Zhang ${ }^{\text {a }}$, Mingzhong Zhang ${ }^{\mathrm{b}}$ \\ ${ }^{\text {a }}$ School of Civil Engineering, Wuhan University, Wuhan, 430072, China \\ ${ }^{\mathrm{b}}$ Department of Civil, Environmental and Geomatic Engineering, University College London, \\ London, WC1E 6BT, UK
}

\begin{abstract}
This paper presents an experimental study on the effect of anode format (carbon fibre sheet $(\mathrm{Cs})$, mesh $(\mathrm{Cm})$ and plate $(\mathrm{Cp}))$, current density $\left(0,1,2\right.$, and $3 \mathrm{~A} / \mathrm{m}^{2}$ referred to the surface area of reinforcement), and fly ash content (plain concrete, 10\%, 20\% and 30\% replacement by weight of cement) on the efficiency of electrochemical chloride extraction (ECE). The results showed the total extracted chloride contents of samples treated with different anodes had an order of $\mathrm{Cs}>\mathrm{Cm}>\mathrm{Cp}$. The distribution of anodic reaction products indicated that only a small part of Cs played as anode because of the insulation in its transverse direction while $\mathrm{Cm}$ performed better conductivity uniformity and accordingly higher usage. With the increase of current density, the extracted chloride content improved, but the improvement was very limited when the current density kept rising. The incorporation of fly ash led to $12 \% \sim 153.1 \%$ improvement in extracted chlorides. After ECE, the measured residual free chloride content in concrete did not change with current density or fly ash content, except for the cases when current density was increased from 0 to $1 \mathrm{~A} / \mathrm{m}^{2}$. The additional extracted chlorides with increasing current density or fly ash content can be attributed to the dissolution of bound chlorides. The contribution of increasing compactness by adding fly ash was offset by the destruction of Friedel's salt and the resulting release of chloride ions in the alkali environment and under the impressed currents.
\end{abstract}

Keywords: Corrosion; Electrochemical rehabilitation; Fly ash; Blended concrete; Carbon fibre anode

\section{Introduction}

Durability is a main concern for safety of reinforced concrete structures [1-3]. Corrosion of steel reinforcements is considered as the major cause of concrete deteriorations, followed by frost action in cold climates and physico-chemical effects in aggressive environments [4]. On the one hand, chloride ions could disrupt the passive films surrounding the steel reinforcements even in an alkaline environment. On the other hand, chloride ions act as a catalyst rather than as a direct reactant in corrosion reactions, which aggravates the corrosion behaviour $[5,6]$.

Based on this fact, current specifications seriously limit the chloride content in concrete. Chloride ions exist in concrete in the forms of "free" and "bound". The free chlorides are mobile whilst the bound chlorides are fixed. Therefore, only free chlorides are relevant to the corrosion of reinforcements, and the bound chlorides are not available to initiate corrosion. ACI 318 limits the maximum free chloride content to be lower than $0.15 \%$ by weight of cement for concrete structures exposed to chlorides in service. The corresponding threshold in Chinese code is $0.06 \%$ by weight of cement. To reduce the chloride-induced hazards, controlling begins from proper material design and continues with repairing in service.

For already corroded constructions, repairing is a solution. Traditional repair techniques, e.g. replacing the old concrete with chloride-free concrete, are not durable solutions, because corrosion of steel reinforcements in concrete is essentially an electrochemical process. Two electrochemical protection methods, cathodic protection (CP) and electrochemical chloride extraction (ECE), are

\footnotetext{
*Corresponding author. Email address: lishan@whu.edu.cn (S. Li)
} 
appropriate and effective for chloride-contaminated reinforced concrete structures [7-10]. During ECE treatment, the chemical reactions that occurred at the anode can be expressed as follows $[11,12]$ :

$$
\begin{aligned}
& 2 \mathrm{H}_{2} \mathrm{O}+\mathrm{O}_{2}+4 \mathrm{e}^{-} \rightarrow 4 \mathrm{OH}^{-} \\
& 2 \mathrm{H}_{2} \mathrm{O}+2 \mathrm{e}^{-} \rightarrow 4 \mathrm{OH}^{-}+\mathrm{H}_{2}
\end{aligned}
$$

Cathodic reactions can be described as Eqs. (3)-(5). The reaction showed in Eq. (5) can be suppressed by keeping the $\mathrm{pH}$ of the electrolyte sufficiently high above approximately $9[13,14]$.

$$
\begin{aligned}
& 4 \mathrm{OH}^{-} \rightarrow 2 \mathrm{H}_{2} \mathrm{O}+\mathrm{O}_{2}+4 \mathrm{e}^{-} \\
& 2 \mathrm{Cl}^{-} \rightarrow \mathrm{Cl}^{2}+2 \mathrm{e}^{-} \\
& 2 \mathrm{H}_{2} \mathrm{O} \rightarrow 4 \mathrm{H}^{+}+\mathrm{O}_{2}+4 \mathrm{e}^{-}
\end{aligned}
$$

The differences between $\mathrm{CP}$ and ECE involve impressed current value and operating duration. The impressed current density of ECE is much higher than that of CP. The current density for CP is 2 20 mA/m ${ }^{2}$ [15], while ECE usually utilizes a current density of $0.5 \sim 5 \mathrm{~A} / \mathrm{m}^{2}$ [14]. In addition, CP is operated throughout the entire service life of structures, whereas ECE is usually implemented for only several weeks, so the installed anode could be temporary. Both methods have been proven to be effective to improve the durability and thus extend service life of reinforced concrete structures. Considering their respective characteristics, CP is suitable for structures exposed to marine environments (e.g. wet-dry exposures at the off-shore and immersion exposures for sub-sea structures) for a long time, while ECE is suitable for the chloride-contaminated reinforced concrete structures not exposed to aggressive environments, including de-icing application, use of contaminated water, aggregates and intentional additions of chloride-based admixtures during concrete mixing [9]. It has been reported that ECE efficiency can be affected by many factors, such as current density, water/binder $(\mathrm{w} / \mathrm{b})$ ratio, electrolyte type. It was found that the amounts of removed chlorides increased with the applied current density, water/binder ratio and treatment time and 40-55\% of the total chlorides can be removed from concrete within a relatively short period $[12,16,17]$. To further improve the ECE efficiency, some researchers introduced $\mathrm{SiO}_{3}{ }^{2-}$ into anolyte [18] and increased operation temperatures [19]. It was indicated that introducing $\mathrm{SiO}_{3}{ }^{2-}$ into anolyte and increasing operation temperatures resulted in an improvement in ECE efficiency but the improvement was very limited. The selection of an appropriate anode system is the key for the successful operation of ECE and becomes a hot topic. A good anode system should keep its electrical and mechanical integrity even suffering serious corrosion degradations. Traditional anodes for ECE such as stainless steel mesh and titanium mesh can be easily damaged during operation [20], and thus are not widely used. Nowadays, researchers are dedicating to find a new ECE anode system and assess its stability. Conductive cement-based mortar and carbon fibre sheet (Cs) are potential choices. Conductive cement-based mortar anode has advantages in terms of low cracking risk and good electrical conductivity. The tests on a magnesium phosphate cement (MPC) [21,22] and conductive cement paste showed that very close chloride removal efficiencies with traditional anodes were obtained, while the conductive cement-based mortar anodes were more resistant to corrosion than traditional anodes during operation. This kind of conductive cement-based mortar anode may exhibit its multifunctions for both structural strengthening and ECE operating, but the major drawback is its permanent installation, which may betray the ECE characteristic of temporary operating. Cs anode 
solved the problem of permanent installation. Zhu et al. [23-25] and Lu et al. [26] adopted Cs as anode, which can be placed around the protected structures temporarily and removed after ECE treatment. It was found Cs anode could keep its integrity in mechanical and electrical properties during electrochemical treatment. However, it should be noted that carbon fibres are unidirectional, so $\mathrm{Cs}$ is insulated in the transverse direction. Therefore, carbon fibre mesh $(\mathrm{Cm})$ may be a better option for ECE treatment because it is bi-directional textured and can achieve uniform electrical conductivity.

For new buildings serving in a chloride-rich environment, controlling could begin from material design. The incorporation of mineral additions in concrete such as fly ash is very popular for several reasons. Firstly, fly ash could bind more chlorides and thereby reduce free chloride content. Secondly, fly ash has high reactivity and fine particles [27-30]. As a result, the incorporation of fly ash could increase the concrete compactness and reduce chloride permeability to a large extent $[31,32]$. However, once reinforced concrete structures containing fly ash are invaded by chlorides, chlorides may be more difficult to be extracted due to its compactness and superior chloride binding capacity. Many researchers agreed with this speculation $[33,34]$. Nevertheless, this speculation has not been verified up to now. A comparison between the concrete specimen with $32 \%$ ground granulated blastfurnace slag (GGBS) and 17\% fly ash and plain concrete showed a close ECE efficiency [35]. This may be ascribed to the small sample size or the effects of GGBS and fly ash offset each other. Moreover, the effect of fly ash on ECE efficiency was not discussed separately. Thus, it is of great importance for the wide application of ECE technique to understand the influence of fly ash on its efficiency and the mechanism behind it.

In this study, $\mathrm{Cm}$ with a better electrical uniformity was adopted as ECE anode. The effects of fly ash addition $(0,10 \%, 20 \%$ and $30 \%)$ and current density $\left(0,1,2\right.$, and $\left.3 \mathrm{~A} / \mathrm{m}^{2}\right)$ on the ECE efficiency were evaluated. To compare the effectiveness of different carbon fibre anode format, specimens treated with $\mathrm{Cs}$ and carbon fibre plate $(\mathrm{Cp})$ anodes were designed. Firstly, the content of extracted chlorides as a function of time was obtained and compared by titrating the anolyte every $2 \mathrm{~d}$ during ECE treatment. Subsequently, the content of residual chlorides in concrete was measured by titrating the dissolved mortar powder solution to assess the corrosion risk after ECE treatment. Finally, the mercury intrusion porosimetry (MIP) and thermo-gravimetric analysis (TGA) were carried out to estimate the effects of ECE and the addition of fly ash on the porosity and chemical composition of concrete samples.

\section{Experimental program}

\subsection{Specimen details}

Table 1 shows the specimen details. In total, sixteen specimens were fabricated to investigate the effects of current density and fly ash content, and another two specimens were designed to estimate the effect of anode format on ECE efficiency. The diameter and height of the specimens were 110 $\mathrm{mm}$ and $300 \mathrm{~mm}$, respectively. P.O 42.5 Portland cement as per Chinese standard GB175-2007 [36] was used to prepare concrete and Class I fly ash as per Chinese standard GB1596-2005 [37] was selected to replace Portland cement with replacement ratios of $0,10 \%, 20 \%$ and $30 \%$. The corresponding international codes for the two referenced Chinese standards are ACI 116R [38] and ACI 232.2R [39]. The w/b ratio for all specimens was kept the same as 0.5 . Natural sand was used as fine aggregates and continuous grading stones with maximum diameter of $20 \mathrm{~mm}$ were used as coarse aggregates. $3 \% \mathrm{NaCl}$ regarding mass of binder was intermixed into tap water to simulate a chloridecontaminated environment. The mix proportions of concrete with $0,10 \%, 20 \%$ and $30 \%$ replacement 
of fly ash are listed in Table 2 . The corresponding $28 \mathrm{~d}$ compressive strengths are $32.16,30.27,30.83$ and $31.85 \mathrm{MPa}$, respectively. The embedded reinforcement in concrete was HRB 400 steel rebar with a length of $490 \mathrm{~mm}$ and a diameter of $20 \mathrm{~mm}$. To guarantee the length directly contacted to concrete being $200 \mathrm{~mm}$, insulated epoxy and PVC tubes were applied onto the two ends of the steel reinforcements. Fig. 1 shows the geometry details of the specimens, which were wrapped with plastic films during curing to prohibit chloride ion loss due to water maintenance.

\subsection{ECE treatments}

As discussed before, $\mathrm{Cm}$ would be a better option for ECE anodes because of its uniform electrical conductivity. Therefore, three different carbon fibre productions $(\mathrm{Cs}, \mathrm{Cp}$, and $\mathrm{Cm}$ ) were utilized and compared, as showed in Fig. 2. Cs and Cm anodes were positioned around the specimens, as illustrated in Fig. 3, while Cp was placed in solution. The selected current densities included 0, 1, 2, and $3 \mathrm{~A} / \mathrm{m}^{2}$ (referred to the surface area of steel reinforcement exposed to concrete). The ECE current was imposed by a DC-regulated power supply, which had voltage and current capacities of $300 \mathrm{~V}$ and $1 \mathrm{~A}$ in increments of $10 \mathrm{mV}$ and $1 \mathrm{~mA}$, respectively. Fig. 4 shows the arrangement of ECE. The saturated $\mathrm{Ca}(\mathrm{OH})_{2}$ solution was adopted as electrolyte. It was reported that the evolution of chlorine gas can be suppressed by keeping the $\mathrm{pH}$ of the electrolyte high enough, i.e. above approximately 9 [13]. Therefore, in order to reduce the evolution of chlorine gas and keep the $\mathrm{pH}$ above 9, the saturated $\mathrm{Ca}(\mathrm{OH})_{2}$ solution was replaced every $2 \mathrm{~d}$. The cathodic currents were applied on steel reinforcement surface for $28 \mathrm{~d}$.

\subsection{Test methods}

The electrolyte was collected every $2 \mathrm{~d}$ for determining the extracted chloride content, which was measured by titrating with $\mathrm{AgNO}_{3}$ solution. To increase the reliability of the results, the chloride content was also measured by a Chloride Ion Content Tester. After $28 \mathrm{~d}$ of ECE treatment, mortar powders at each $15 \mathrm{~mm}$ depth were obtained by a drilling machine. The powders were regulated through a $630 \mu \mathrm{m}$ sieve and by repeated grinding of a sieve residue. $20 \mathrm{~g}$ powders were mixed into $200 \mathrm{ml}$ distilled water. After stirring and immersing for $24 \mathrm{~h}$, the water-solution chloride content in concrete was measured by titrating.

ECE treatment may alter the hydration products of concrete bulk and affect the porosity of concrete, especially for concrete containing fly ash which has a slower hydration process and finer particles in comparison with plain concrete. Thus, in order to estimate this effect, the analysis of porosity in concrete was performed by means of MIP and TGA was conducted to detect the changes of hydration products in concrete at a heating rate of $15{ }^{\circ} \mathrm{C} / \mathrm{min}$ from $25{ }^{\circ} \mathrm{C}$ to $800{ }^{\circ} \mathrm{C}$. The main emphasis was placed on the effects of fly ash and ECE treatment, so specimens I2F0 and I2F30 were selected for testing.

\section{Results and discussion}

\subsection{Effect of anode format}

Fig. 5 shows the cumulative extracted chloride ion content of different anode formats along with ECE time. During the whole ECE process, the total extracted chloride ion content of samples had an order of $\mathrm{Cs}>\mathrm{Cm}>\mathrm{Cp}$. After the $28 \mathrm{~d}$ of treatment, the cumulative extracted chloride content was $5.83 \mathrm{~g}$, $4.80 \mathrm{~g}$, and $4.52 \mathrm{~g}$, respectively. $\mathrm{Cp}$ was placed at one side and thus the current cannot be applied uniformly, while the other two anodes were installed in a concentric form. As a result, the test using $\mathrm{Cp}$ as anode performed the lowest extracted chloride content. An interesting phenomenon can be observed in Fig. 6 that only a small upper region of Cs was found to arise yellow products due to anodic reactions and played as the ECE anode, while the rest part of Cs did not work. This is because 
carbon fibres are unidirectional, and the sheet was insulated in the transverse direction. The upper region was conductive due to contacting, while the rest of the sheet was insulated. In contrast, the entire $\mathrm{Cm}$ participated in ECE reactions. The slightly lower extracted chloride content may be due to the much smaller surface area in comparison with Cs.

\subsection{Effect of current density}

Fig. 7a d shows the cumulative chloride content in the anolyte against ECE time of specimens treated with ECE current densities of $0,1,2$, and $3 \mathrm{~A} / \mathrm{m}^{2}$, respectively, which was measured by titrating the chloride ion concentration in electrolyte every $2 \mathrm{~d}$. For the sake of comparison and calculation, the initial chlorides intermixed in concrete, extracted chlorides in the anolyte, remained free chlorides and bound chlorides in concrete samples were all expressed in gram. As seen in Fig. 7a, chlorides presented in anolyte even without electrical field force. The migration of chlorides into anolyte was due to the force of concentration gradient. By comparing the specimens with the same mix proportion, increasing ECE current density can markedly increase the total extracted chloride content, which is consistent with findings reported in previous studies. When the current densities increased from 1 to $2 \mathrm{~A} / \mathrm{m}^{2}$, the improvement in extracted chloride contents were $30.1 \% \sim 56.4 \%$. When current densities changed from 2 to $3 \mathrm{~A} / \mathrm{m}^{2}$, the improvement in extracted chloride contents varied from $5.3 \%$ to $53.2 \%$. For the concrete samples with $30 \%$ fly ash, the extracted chloride content was only increased by 0.64 $\mathrm{g}$ when the current density increased from $2 \mathrm{~A} / \mathrm{m}^{2}$ to $3 \mathrm{~A} / \mathrm{m}^{2}$. The improvement was only $5.3 \%$, which indicated that the rise in ECE efficiency induced by improving current densities was limited.

After $28 \mathrm{~d}$ of ECE treatment, the profile of residual free chlorides in mortar was obtained by titrating the dissolved mortar powders at different depths of columns. Fig. 8 shows the typical distribution of residual free chlorides in concrete samples. It can be observed in all cases that the innermost mortar had the lowest free chlorides while the depth of 15-30 mm showed the highest chloride content. The free chlorides migrated from the cathode to the anode due to the electrical field force and thus the lowest free chlorides at the innermost mortar were observed. When the chlorides moved to the concrete surface, they can be easily and timely leaked out to the electrolyte due to both electrical field force and concentration gradient. As a result, an accumulation of free chlorides was observed between $15 \mathrm{~mm}$ and $30 \mathrm{~mm}$.

To compare the content of the residual free chlorides in mortar with the content of the extracted chlorides present in the anolyte, total free chlorides in an individual specimen were calculated and expressed in gram. The change in residual free chloride contents with increasing current densities was showed in Fig. 9. When the current density increased from 0 to $1 \mathrm{~A} / \mathrm{m}^{2}$, the free chloride content of specimens I1F0, I1F10, I1F20, and I1F30 was reduced by $48.3 \%, 45.0 \%, 56.7 \%$ and $62.0 \%$, respectively, suggesting the effectiveness of ECE. However, when the current density continued growing to 2 and $3 \mathrm{~A} / \mathrm{m}^{2}$, the residual free chloride content kept stable. It is known that the corrosion of reinforcing steel in concrete is induced by free chlorides rather than bound chlorides. Therefore, this finding indicates that keeping increasing ECE current densities cannot reduce residual free chlorides and accordingly reduce corrosion risks in a further step. Given the side effects of high current density (such as steel/concrete bond loss, and concrete bulk softening), a relatively small ECE current density is better $\left(1 \mathrm{~A} / \mathrm{m}^{2}\right.$ in this study). However, it has been found that larger current density could significantly increase the extracted chloride content. For specimens mixed with $20 \%$ fly ash, the extracted chloride content present in anolyte was $1.37 \mathrm{~g}, 5.16 \mathrm{~g}, 7.67 \mathrm{~g}$ and $11.34 \mathrm{~g}$ after $28 \mathrm{~d}$ of ECE operation with $0,1,2$, and $3 \mathrm{~A} / \mathrm{m}^{2}$ current densities, respectively, whereas the corresponding residual free chloride content was $5.7 \mathrm{~g}, 2.47 \mathrm{~g}, 2.17 \mathrm{~g}$, and $2.38 \mathrm{~g}$, respectively. The additional 
extracted chloride content by imposing larger current densities was a result of the dissolution of bound chlorides. When the content of free chloride ions in pore solution of concrete decreases and the equilibrium is broken, the bound chlorides would dissolve into free chloride ions to form a new balance $[40,41]$.

Subtracting the extracted chlorides and the residual free chlorides from the initial chlorides, the remained bound chlorides can be calculated. As seen in Fig.10, bound chlorides gradually reduced with increasing current density. For example, compared with untreated specimen with a current density of 0 , the residual bound chlorides in specimens with $20 \%$ fly ash (F20 series) decreased by $4.4 \%, 21.3 \%$, and $51.1 \%$ after ECE with 1,2 , and $3 \mathrm{~A} / \mathrm{m}^{2}$ current densities, respectively. This suggests that increasing impressed current density would accelerate the dissolution of bound chlorides. As commonly known, chloride ions in cement can be bound through chemical binding and physical absorption. In the former, $\mathrm{Cl}^{-}$can chemically react with the $\mathrm{C}_{3} \mathrm{~A}$ phase of cement during hydration to form calcium chloroaluminate hydrate $\left(\mathrm{C}_{3} \mathrm{~A} \cdot \mathrm{CaCl}_{2} \cdot 10 \mathrm{H}_{2} \mathrm{O}\right)$, which is generally known as Friedel's salt, and with the $\mathrm{C}_{4} \mathrm{AF}$ phase of cement to form calcium chloroferrite $\left(\mathrm{C}_{3} \mathrm{~F} \cdot \mathrm{CaCl}_{2} \cdot 10 \mathrm{H}_{2} \mathrm{O}\right)[42,43]$; In the latter, $\mathrm{Cl}^{-}$can be physically absorbed by calcium silicate hydrates (C-S-H) [44]. Current investigations have concluded that external electrical field has little effects on the physical absorption behaviour of chlorides [45], but would significantly affect the formation and decomposition of Friedel's salt [46].

The measured $\mathrm{OH}^{-}$concentration at different depths from concrete surface is presented in Table 3. The innermost $\mathrm{OH}^{-}$concentration was larger than that at other positions. The primary reason is the cathodic reaction, which can generate large amount of $\mathrm{OH}^{-}$by imposing ECE current. Some studies found that the $\mathrm{OH}^{-}$concentration after ECE treatment increased with increasing current density [35]. Similar development trend was not observed in this test. Table 3 shows the calculated $\left[\mathrm{Cl}^{-}\right] /\left[\mathrm{OH}^{-}\right]$ ratios. As reported, when $\left[\mathrm{Cl}^{-}\right] /\left[\mathrm{OH}^{-}\right]$molar ratios are higher than 0.6 , steel seems to be no longer protected against corrosion, probably because the iron-oxide film becomes either permeable or unstable under these conditions [47]. As seen in Table 3, all the innermost $\left[\mathrm{Cl}^{-}\right] /\left[\mathrm{OH}^{-}\right]$ratios are below 0.6 , suggesting that the steel reinforcements in all cases were out of corrosion risk.

Fig. 11 shows the measured pore size distribution of concrete specimens before and after ECE using MIP. The corresponding porosities were listed in Table 4. After ECE, the concrete samples were taken from both innermost and outermost positions and then tested separately. It should be noticed that the samples before ECE were tested at the curing time of $28 \mathrm{~d}$. Before ECE, the porosity of specimen I2F0 was $11.8 \%$. After ECE process, the porosities of the innermost and the outermost samples of specimen I2F0 were $13.1 \%$ and $8.5 \%$, respectively. Specimen I2F30 had the same change trend in porosity, i.e. increase at the innermost while decrease at the outermost layer. In general, the ECE treatment could generate $\mathrm{Ca}(\mathrm{OH})_{2}$ to fill the pores and accordingly decrease the porosity, which explained the reduction in porosity of outmost samples after ECE. However, the innermost concrete had a higher porosity due to the additional pores with pore diameter lower than $20 \mathrm{~nm}$, which can be ascribed to the decomposition of C-S-H induced by $\mathrm{Na}^{+}, \mathrm{K}^{+}$and $\mathrm{OH}^{-}$as well as the hydrogen evolution reaction, leading to loose structures around the steel reinforcements. This result was also observed and reported in other studies [48,49].

\subsection{Effect of fly ash content}

It can be observed from Fig. 7 that the extracted chloride ions increased with increasing fly ash content. For the specimens treated with current density of $1 \mathrm{~A} / \mathrm{m}^{2}$ (I1F0, I1F10, I1F20, and I1F30), as shown in Fig. 7b, the extracted chloride content of them was $3.69 \mathrm{~g}, 3.44 \mathrm{~g}, 5.16 \mathrm{~g}$ and $9.10 \mathrm{~g}$ after $28 \mathrm{~d}$ of 
ECE implementation, respectively. For the specimens with current density of $2 \mathrm{~A} / \mathrm{m}^{2}$ (I2F0, I2F10, I2F20, and I2F30), as shown in Fig. 7c, the total extracted chloride content was $4.80 \mathrm{~g}, 5.38 \mathrm{~g}, 7.67$ $\mathrm{g}$ and $12.15 \mathrm{~g}$ at the end of ECE, respectively. For specimens treated with current density of $3 \mathrm{~A} / \mathrm{m}^{2}$, the total chloride content of I3F0, I3F10, I3F20, and I3F30 was $7.06 \mathrm{~g}, 8.23 \mathrm{~g}, 11.34 \mathrm{~g}$ and $12.79 \mathrm{~g}$, respectively (see Fig. 7d). Clearly, more chloride ions could be extracted for specimens with higher fly ash content (except specimen I1F10). The growth in extracted chloride ions resulting from the addition of fly ash varied from $12 \%$ to $153.1 \%$, which was contrary to the assumptions that fly ash has a higher chloride binding ability, higher compactness and thereby a higher resistance to ECE.

Sun et al. [50] reported that fly ash concretes had lower compactness at an early curing age because of the low reactive degrees of fly ash, resulting in a higher ECE efficiency than that of plain concretes. However, it is agreed that fly ash concrete has a higher compactness and lower chloride permeability at the $28 \mathrm{~d}$ of standard curing [51]. The MIP measurement result (see Table 4) also verified that $30 \%$ fly ash concrete sample had lower porosity $(7.2 \%)$ than plain concrete sample $(11.8 \%)$ at the curing age of $28 \mathrm{~d}$. Therefore, when the ECE treatment was applied in this test, the fly ash concrete samples were denser than plain concrete samples. The more extracted chloride ions from fly ash concrete samples were not resulted from the lower compactness. Inversely, the denser matrix of fly ash concrete sample made it more difficult to extract chlorides from it.

Even without ECE treatment, fly ash concrete samples released more chlorides into the anolyte than plain concrete samples, as showed in Fig. 7a. Therefore, one explanation is that $\mathrm{Ca}(\mathrm{OH})_{2}$ solutions helps to release the bound chloride ions in samples. Fly ash concrete has a superior chloride binding capacity mainly because it has a significantly larger amount of $\mathrm{Al}_{2} \mathrm{O}_{3}$ [52]. Some researchers alleged that increasing alkalinity could inhibit the formation of Friedel's salt and even destroy the existing Friedel's salt $[53,54]$. Thus, specimens with fly ash had more Friedel's salt and thus released more free chloride ions into solutions as a result of instability of Friedel's salt in alkali environments.

To support this analysis, DTG tests were conducted for specimens I2F0 and I2F30 before and after ECE treatment. The DTG curves were showed in Fig. 12, where some noticeable peaks existed. The peaks in the temperature region of $250 \sim 350{ }^{\circ} \mathrm{C}$ are mainly due to dehydration of Friedel's salt. Before ECE treatment, the content of Friedel's salt in sample I2F30 was clearly larger than that in sample I2F0, which confirmed the stronger chloride binding capacity of fly ash concrete samples. It can be found that there was no peak in the temperature region of $250 \sim 350{ }^{\circ} \mathrm{C}$ in both $\mathrm{I} 2 \mathrm{~F} 0$ and $\mathrm{I} 2 \mathrm{~F} 30$ samples after ECE treatment. Therefore, electrochemical treatment will remove Friedel's salt by comparing DTG responses before and after ECE. This observation supports our previous analysis.

An interesting phenomenon is that the specimens containing $10 \%$ fly ash always had a little bit lower extracted chloride content than the corresponding specimens without fly ash but caught up later. The specimens with $20 \%$ and $30 \%$ fly ash had similar but insignificant trends, which exhibited overwhelming greater amounts of extracted chloride ions in the later period. The adverse development in the earlier stage and the later stage means that the ECE process was affected by at least two contradictory factors. At the beginning of ECE treatment, the ECE was more difficult for fly ash concrete samples due to their higher compactness and lower chloride permeability. This observation was not very significant for $20 \%$ and $30 \%$ specimens. This was due to that the destruction of Friedel's salt and the resulting release of chloride ions in alkali environment offset and even exceeded the ECE difficulty for fly ash samples induced by high compactness and low chloride permeability. In the later ECE process, more $\mathrm{OH}^{-}$were produced in the cathodic reactions, resulting in a further disparity in the total extracted chloride content between plain concrete samples and fly 
ash concrete samples. Another influential factor was the heat generated by the applied current. The fly ash concrete specimens had much higher resistivity compared with plain concrete, more heats were generated, and thus more physically binding chloride ions desorbed [55].

The residual free chlorides were measured, and the corresponding residual bound chlorides were calculated, as shown in Figs. 7 and 8. The residual free chloride content did not change with fly ash content while the residual bound chlorides reduced gradually with increasing the dosage of fly ash. This observation again supported our previous analysis that the leaching out of bound chlorides is the cause of the additional extracted chlorides by incorporating more fly ash in concrete. With a larger replacement ratio of fly ash, the reduction in bound chlorides was more significant. Specially, for $30 \%$ fly ash replacing specimens, the reduction was much more rapid than others. It is deduced to be caused by the high voltage. Obviously, 30\% fly ash sample has the highest electrical resistance. During the ECE process, the applied voltage was the highest for $30 \%$ fly ash samples. Because ECE could improve the densities and reduce the electrical resistance of samples. In the end of ECE treatment, the applied voltage approached the upper limit of DC power (300V) for 30\% fly ash sample treated with $3 \mathrm{~A} / \mathrm{m}^{2}$ current. High voltages generate high heat, resulting in bound chlorides' desorption. However, in this experiment, specimens with the same current were connected in series, so the feedback voltages did not correspond individual specimens and thus were not recorded in detail. Another probable cause is the break of Friedel's salt and the resulting release of chloride ions in an environment of increasing $\mathrm{OH}^{-}$concentration.

\section{Conclusions}

In this paper, the effects of anode format $\left(\mathrm{Cs}, \mathrm{Cm}\right.$, and $\mathrm{Cp}$ ), current density $\left(0,1,2\right.$, and $\left.3 \mathrm{~A} / \mathrm{m}^{2}\right)$, and fly ash content (replacement ratio included $0,10 \%, 20 \%$ and $30 \%$ ) on the ECE efficiency were investigated experimentally. The extracted chlorides present in anolyte and the residual free chlorides in concrete after ECE were measured and compared. Additionally, MIP and TGA before and after ECE were conducted for selected specimens. Based on the test results, the conclusions can be drawn as follows:

- Although the extracted chloride ion amount using $\mathrm{Cm}$ anode was slightly lower than that using $\mathrm{Cs}$, the much smaller surface area of the former should be responsible. Cs was not fully utilized due to its insulation in the transverse direction. Therefore, $\mathrm{Cm}$ is a preferential optio $\mathrm{n}$ for ECE anode because of its better conductivity uniformity and accordingly higher usage.

- Increasing current density could significantly improve the extracted chloride content. The improvement varied from $5.3 \%$ to $56.4 \%$ for every $1 \mathrm{~A} / \mathrm{m}^{2}$ increase in ECE current density. However, the corrosion-related remaining free chlorides in all cases (except the cases when current density changed from 0 to $1 \mathrm{~A} / \mathrm{m}^{2}$ ) was kept at a certain level. The effectiveness of ECE was proven, because both the extracted chlorides and residual free chlorides changed to a large extent when current density changed from 0 to $1 \mathrm{~A} / \mathrm{m}^{2}$. When the current density was increased, the additional extracted chlorides came from the release of bound chlorides while the residual free chlorides were changeless. Therefore, the large current density only broke the chemical balance between free chlorides and bound chlorides and cannot reduce the residual free chlorides and corrosion risk.

- Increasing the fly ash content could markedly improve the extracted chlorides, and the improvement ranged from $12 \%$ to $153.1 \%$. Nevertheless, the residual free chlorides did not change with fly ash content. The leaching out of bound chlorides contributed to the additional extracted chlorides by incorporating more fly ash in concrete. The leaching out of bound chlorides was mainly due to the increasing alkalinity and temperatures for fly ash concrete samples. The higher 
compactness of fly ash concrete made it more difficult to extract chlorides, but it was offset by the release of bound chlorides when the fly ash content increased.

\section{Acknowledgments}

This work was supported by the Natural Science Foundation of China (No.51578428), the Technology Innovation Major Program of Hubei Province of China (No. 2016AAA025) and UKChina Joint Research and Innovation Partnership Fund PhD Placement Programme (201806270441). The authors gratefully acknowledge the financial support and thank Hongjun Liang, Wenkai Yi, Yue Huang, Siyu Wang for their help with experiments.

\section{References}

[1] Atta A, Ali N, Taman M. Efficiency and corrosion characteristics of high performance cementitious composites as a strengthening material. Compos Part B Eng 2019;166:341-51. https://doi.org/10.1016/j.compositesb.2018.11.105.

[2] Berrocal CG, Fernandez I, Lundgren K, Löfgren I. Corrosion-induced cracking and bond behaviour of corroded reinforcement bars in SFRC. Compos Part B Eng 2017;113:123-37. https://doi.org/10.1016/j.compositesb.2017.01.020.

[3] Nguyen W, Duncan JF, Devine TM, Ostertag CP. Electrochemical polarization and impedance of reinforced concrete and hybrid fiber-reinforced concrete under cracked matrix conditions. Electrochimica Acta 2018;271:319-36. https://doi.org/10.1016/j.electacta.2018.03.134.

[4] Mehta PK. Concrete durability-fifty years progress. vol. 126-1, 1991, p. 1-31.

[5] Liang H, Li S, Lu Y, Hu J, Liu Z. Electrochemical performance of corroded reinforced concrete columns strengthened with fiber reinforced polymer. Compos Struct 2019;207:576-88. https://doi.org/10.1016/j.compstruct.2018.09.028.

[6] Zhou Y, Zheng Y, Pan J, Sui L, Xing F, Sun H, et al. Experimental investigations on corrosion resistance of innovative steel-FRP composite bars using X-ray microcomputed tomography. Compos Part B Eng 2019;161:272-84. https://doi.org/10.1016/j.compositesb.2018.10.069.

[7] Koleva DA, Guo Z, van Breugel K, de Wit JHW. Conventional and pulse cathodic protection of reinforced concrete: Electrochemical behavior of the steel reinforcement after corrosion and protection. Mater Corros 2009;60:344-54. https://doi.org/10.1002/maco.200805150.

[8] Jing $\mathrm{X}, \mathrm{Wu}$ Y. Electrochemical studies on the performance of conductive overlay material in cathodic protection of reinforced concrete. Constr Build Mater 2011;25:2655-62. https://doi.org/10.1016/j.conbuildmat.2010.12.015.

[9] Liu Y, Shi X. Electrochemical chloride extraction and electrochemical injection of corrosion inhibitor in concrete: state of the knowledge. Corros Rev 2009;27. https://doi.org/10.1515/CORRREV.2009.27.1-2.53.

[10]Fan L, Bao Y, Meng W, Chen G. In-situ monitoring of corrosion-induced expansion and mass loss of steel bar in steel fiber reinforced concrete using a distributed fiber optic sensor. Compos Part B Eng 2019;165:679-89. https://doi.org/10.1016/j.compositesb.2019.02.051.

[11] Yeih W, Chang JJ, Hung CC. Selecting an adequate procedure for the electrochemical chloride removal. Cem Concr Res 2006;36:562-70. https://doi.org/10.1016/j.cemconres.2005.12.008.

[12] de Almeida Souza LuanR, de Medeiros MHF, Pereira E, Capraro APB. Electrochemical chloride extraction: Efficiency and impact on concrete containing $1 \%$ of $\mathrm{NaCl}$. Constr Build Mater 2017;145:435-44. https://doi.org/10.1016/j.conbuildmat.2017.04.010.

[13]Huang T, Huang X, Wu P. Review of recent developments of electrochemical chloride extraction on reinforced concrete in civil engineering. Int J Electrochem Sci 2014;9:9. 
[14] Sharp SR, Clemeña GG, Virmani YP, Stoner GE, Kelly RG. Electrochemical chloride extraction: Influence of concrete surface on treatment. Charlottesville, VA: Virginia Transportation Research Council; 2002.

[15]222R-01 Protection of Metals in Concrete Against Corrosion. American Concrete Institute; 2001. [16] Mao L, Hu Z, Xia J, Feng G, Azim I, Yang J, et al. Multi-phase modelling of electrochemical rehabilitation for ASR and chloride affected concrete composites. Compos Struct 2019;207:17689. https://doi.org/10.1016/j.compstruct.2018.09.063.

[17]Fajardo G, Escadeillas G, Arliguie G. Electrochemical chloride extraction (ECE) from steelreinforced concrete specimens contaminated by "artificial" sea-water. Corros Sci 2006;48:110 25. https://doi.org/10.1016/j.corsci.2004.11.015.

[18] Shan H, Xu J, Wang Z, Jiang L, Xu N. Electrochemical chloride removal in reinforced concrete structures: Improvement of effectiveness by simultaneous migration of silicate ion. Constr Build Mater 2016;127:344-52. https://doi.org/10.1016/j.conbuildmat.2016.09.137.

[19]Ueda T, Wakitani K, Nanasawa A. Influence of electrolyte temperature on efficiency of electrochemical chloride removal from concrete. Electrochimica Acta 2012;86:23-7. https://doi.org/10.1016/j.electacta.2012.05.026.

[20]Carmona J, Garcés P, Climent MA. Efficiency of a conductive cement-based anodic system for the application of cathodic protection, cathodic prevention and electrochemical chloride extraction to control corrosion in reinforced concrete structures. Corros Sci 2015;96:102-11. https://doi.org/10.1016/j.corsci.2015.04.012.

[21] Lin H, Li Y, Li Y. A study on the deterioration of interfacial bonding properties of chloridecontaminated reinforced concrete after electrochemical chloride extraction treatment. Constr Build Mater 2019;197:228-40. https://doi.org/10.1016/j.conbuildmat.2018.11.196.

[22] Li Y, Liu X, Wu M, Bai W. Research of electrochemical chloride extraction and reinforcement of concrete column using MPC-bonded carbon fiber reinforced plastic sheet \& mesh. Constr Build Mater 2017;153:436-44. https://doi.org/10.1016/j.conbuildmat.2017.07.131.

[23]Zhu J-H, Wei L, Zhu M, Sun H, Tang L, Xing F. Polarization induced deterioration of reinforced concrete with CFRP anode. Materials 2015;8:4316-31. https://doi.org/10.3390/ma8074316.

[24]Zhu J, Su M, Huang J, Ueda T, Xing F. The ICCP-SS technique for retrofitting reinforced concrete compressive members subjected to corrosion. Constr Build Mater 2018;167:669-79. https://doi.org/10.1016/j.conbuildmat.2018.01.096.

[25]Zhu J-H, Wei L, Wang Z, Liang CK, Fang Y, Xing F. Application of carbon-fiber-reinforced polymer anode in electrochemical chloride extraction of steel-reinforced concrete. Constr Build Mater 2016;120:275-83. https://doi.org/10.1016/j.conbuildmat.2016.05.103.

[26] Lu Y, Hu J, Li S, Tang W. Active and passive protection of steel reinforcement in concrete column using carbon fibre reinforced polymer against corrosion. Electrochimica Acta 2018;278:124-36. https://doi.org/10.1016/j.electacta.2018.05.037.

[27]Güneyisi E, Gesoğlu M, Karaboğa F, Mermerdaş K. Corrosion behavior of reinforcing steel embedded in chloride contaminated concretes with and without metakaolin. Compos Part B Eng 2013;45:1288-95. https://doi.org/10.1016/j.compositesb.2012.09.085.

[28]Khan MI, Siddique R. Utilization of silica fume in concrete: Review of durability properties. Resour Conserv Recycl 2011;57:30-5. https://doi.org/10.1016/j.resconrec.2011.09.016.

[29] Yao ZT, Ji XS, Sarker PK, Tang JH, Ge LQ, Xia MS, et al. A comprehensive review on the applications of coal fly ash. Earth-Sci Rev 2015;141:105-21. 
https://doi.org/10.1016/j.earscirev.2014.11.016.

[30] Shi C. Effect of mixing proportions of concrete on its electrical conductivity and the rapid chloride permeability test (ASTM C1202 or ASSHTO T277) results. Cem Concr Res 2004;34:537-45. https://doi.org/10.1016/j.cemconres.2003.09.007.

[31]Cheewaket T, Jaturapitakkul C, Chalee W. Long term performance of chloride binding capacity in fly ash concrete in a marine environment. Constr Build Mater 2010;24:1352-7. https://doi.org/10.1016/j.conbuildmat.2009.12.039.

[32]Zhang W, Ba H, Chen S. Effect of fly ash and repeated loading on diffusion coefficient in chloride migration test. Constr Build Mater 2011;25:2269-74. https://doi.org/10.1016/j.conbuildmat.2010.11.016.

[33]Dong B, Gu Z, Qiu Q, Liu Y, Ding W, Xing F, et al. Electrochemical feature for chloride ion transportation in fly ash blended cementitious materials. Constr Build Mater 2018;161:577-86. https://doi.org/10.1016/j.conbuildmat.2017.11.123.

[34]Ismail M, Muhammad B. Electrochemical chloride extraction effect on blended cements. Adv Cem Res 2011;23:241-8. https://doi.org/10.1680/adcr.2011.23.5.241.

[35]Jin Z, Hou D, Zhao T. Electrochemical chloride extraction (ECE) based on the high performance conductive cement-based composite anode. Constr Build Mater 2018;173:149-59. https://doi.org/10.1016/j.conbuildmat.2018.03.241.

[36]GB175-2007 Common portland cement. Beijing: General Administration of Quality Supervision, Inspection and Quarantine of the People's Republic of China; 2007.

[37]GB1596-2005 Fly ash used for cement and concrete. Beijing: General Administration of Quality Supervision, Inspection and Quarantine of the People's Republic of China; 2005.

[38]ACI 116R Cement and Concrete Terminology. Farmington Hills, Michigan: American Concrete Institute; 2000.

[39]ACI 232.2R Use of Fly Ash in Concrete. Farmington Hills, Michigan: American Concrete Institute; 1996.

[40] Yao W, Zhao Z. Chloride transference during electrochemical chloride extraction process. Sci China Technol Sci 2010;53:1466-70. https://doi.org/10.1007/s11431-010-3135-0.

[41]Buenfeld NR, Glass GK, Hassanein AM, Zhang J-Z. Chloride Transport in Concrete Subjected to Electric Field. J Mater Civ Eng 1998;10:220-8. https://doi.org/10.1061/(ASCE)08991561(1998)10:4(220).

[42] Suryavanshi AK, Scantlebury JD, Lyon SB. The binding of chloride ions by sulphate resistant portland cement. Cem Concr Res 1995;25:581-92. https://doi.org/10.1016/0008-8846(95)00047G.

[43] Islam J, Collins F, Aldridge LP, Gates W. Effect of pore characteristics and chloride binding on time-dependent chloride diffusion into cementitious material. Corros Prev 2016:10.

[44]Geng J, Easterbrook D, Li L, Mo L. The stability of bound chlorides in cement paste with sulfate attack. Cem Concr Res 2015;68:211-22. https://doi.org/10.1016/j.cemconres.2014.11.010.

[45] He Z, Shi C, Hu X, Zhang J. Development on migration characteristic and interactions of chloride ion in cement-based materials under applied voltages. J Chin Ceram Soc 2015;43:1111-9.

[46] Chu H, Zhang B, Zhao S, Guo M, Liang Y, Jiang L, et al. Effect of electric current on the stability of bound chloride. Cem Concr Compos 2019;103:71-9. https://doi.org/10.1016/j.cemconcomp.2019.04.015.

[47]Mehta PK, Monteiro PJM. Concrete microstructure, properties and materials. McGraw-Hill; 
2001.

[48] Castellote M, Andrade C, Alonso MC. Changes in concrete pore size distribution due to electrochemical chloride migrateon trials. ACI Mater J 1999;96:314-9.

[49] Siegwart M, Lyness JF, McFarland BJ. Change of pore size in concrete due to electrochemical chloride extraction and possible implications for the migration of ions. Cem Concr Res 2003;33:1211-21. https://doi.org/10.1016/S0008-8846(03)00047-4.

[50] Sun W, Gao X, Yang Y, Su A. Efficiency of electrochemical chloride extraction from concretes with different mixing proportions. Corros Sci Prot Technol 2009;21:308-311.

[51] Saha AK. Effect of class F fly ash on the durability properties of concrete. Sustain Environ Res 2018;28:25-31. https://doi.org/10.1016/j.serj.2017.09.001.

[52] Thomas MDA, Hooton RD, Scott A, Zibara H. The effect of supplementary cementitious materials on chloride binding in hardened cement paste. Cem Concr Res 2012;42:1-7. https://doi.org/10.1016/j.cemconres.2011.01.001.

[53]Justnes DH. A review of chloride binding in cementious system. Nord Concr Res-Publ 1998:17.

[54]Ipavec A, Vuk T, Gabrovšek R, Kaučič V. Chloride binding into hydrated blended cements: The influence of limestone and alkalinity. Cem Concr Res 2013;48:74-85. https://doi.org/10.1016/j.cemconres.2013.02.010.

[55]Nguyen HYT, Pansuk W, Sancharoen P. The effects of electro-chemical chloride extraction on the migration of ions and the corrosion state of embedded steel in reinforced concrete. KSCE J Civ Eng 2018;22:2942-50. https://doi.org/10.1007/s12205-017-2022-7. 


\section{Figures}
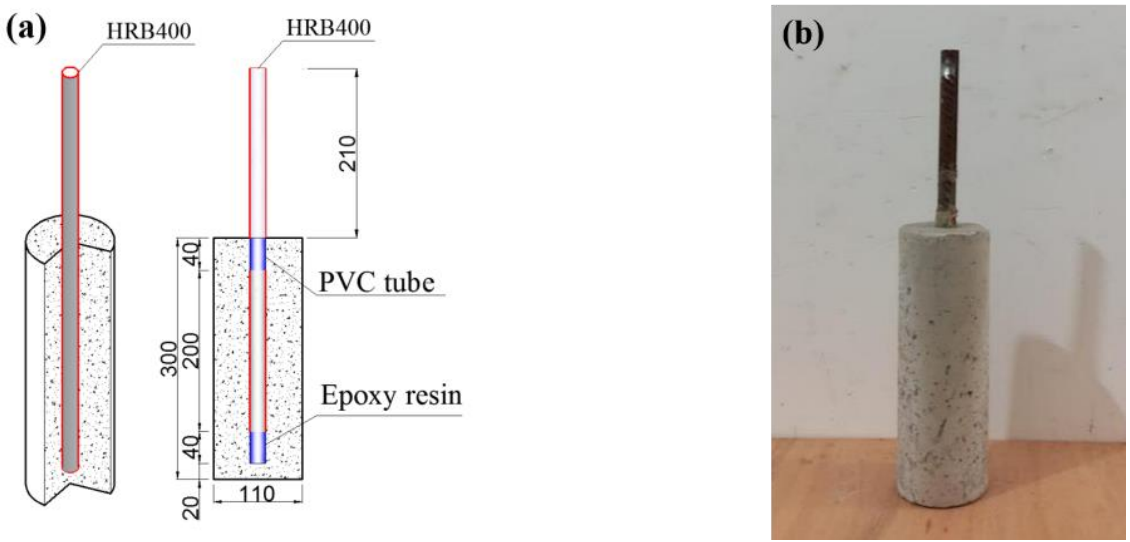

Fig. 1. Specimen details: (a) dimension diagram; (b) photograph
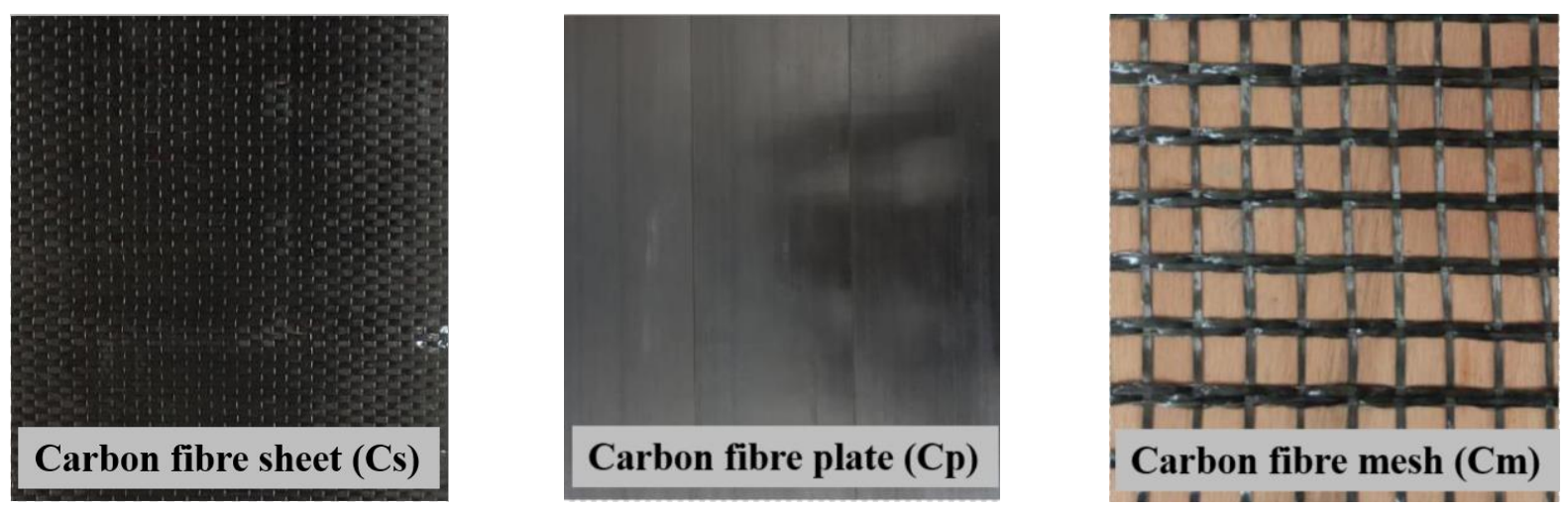

Fig. 2. Photographs of different carbon fibre production format

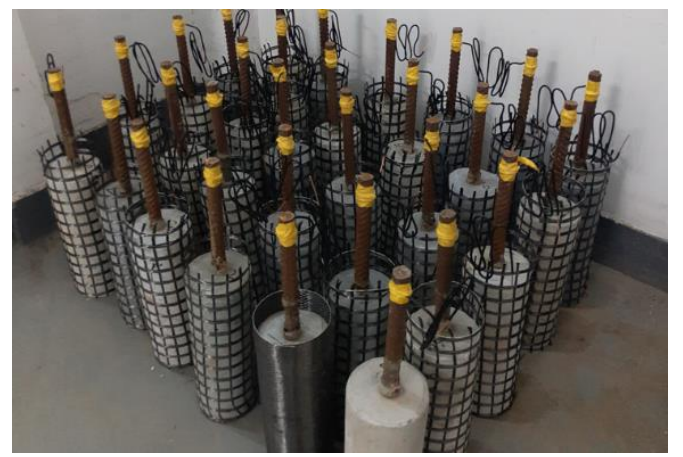

Fig. 3. Anode installation

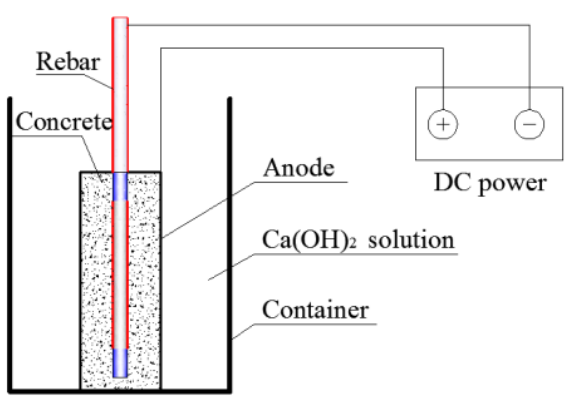

Fig. 4. Arrangement of ECE 


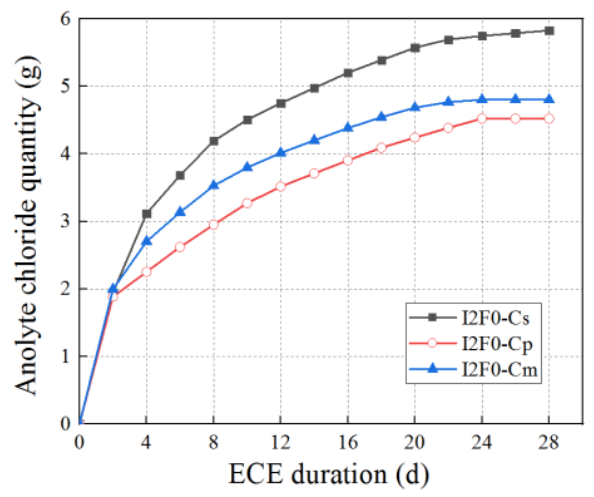

Fig. 5. Cumulative content of extracted chloride ion with ECE time of specimens using different anodes
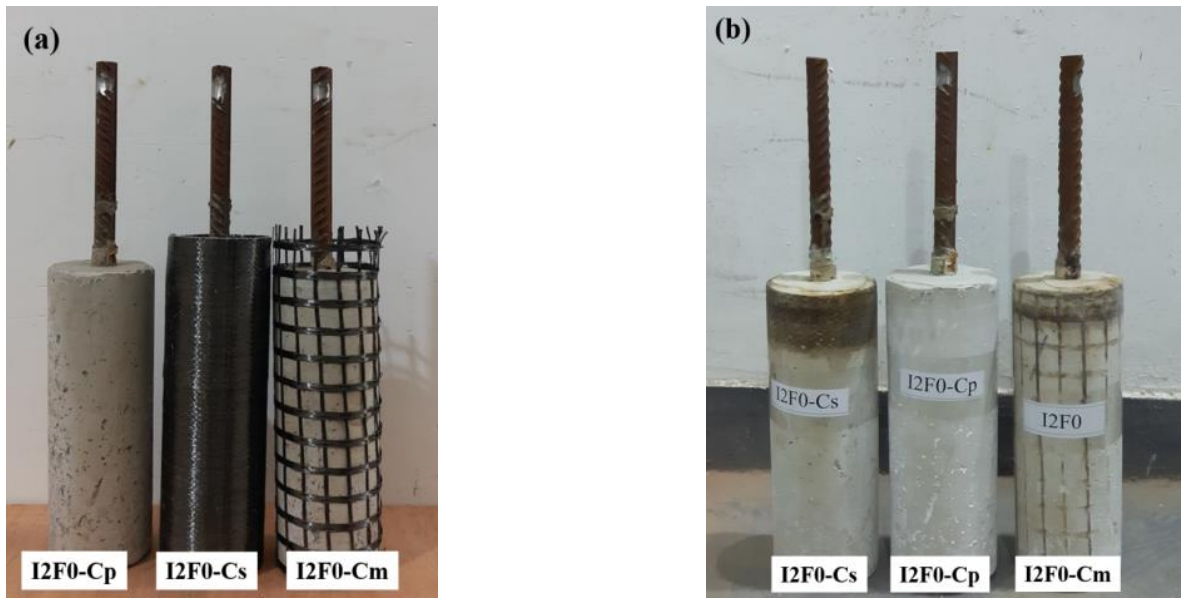

Fig. 6. Specimens treated with different ECE anodes: (a) before ECE; (b) after ECE 

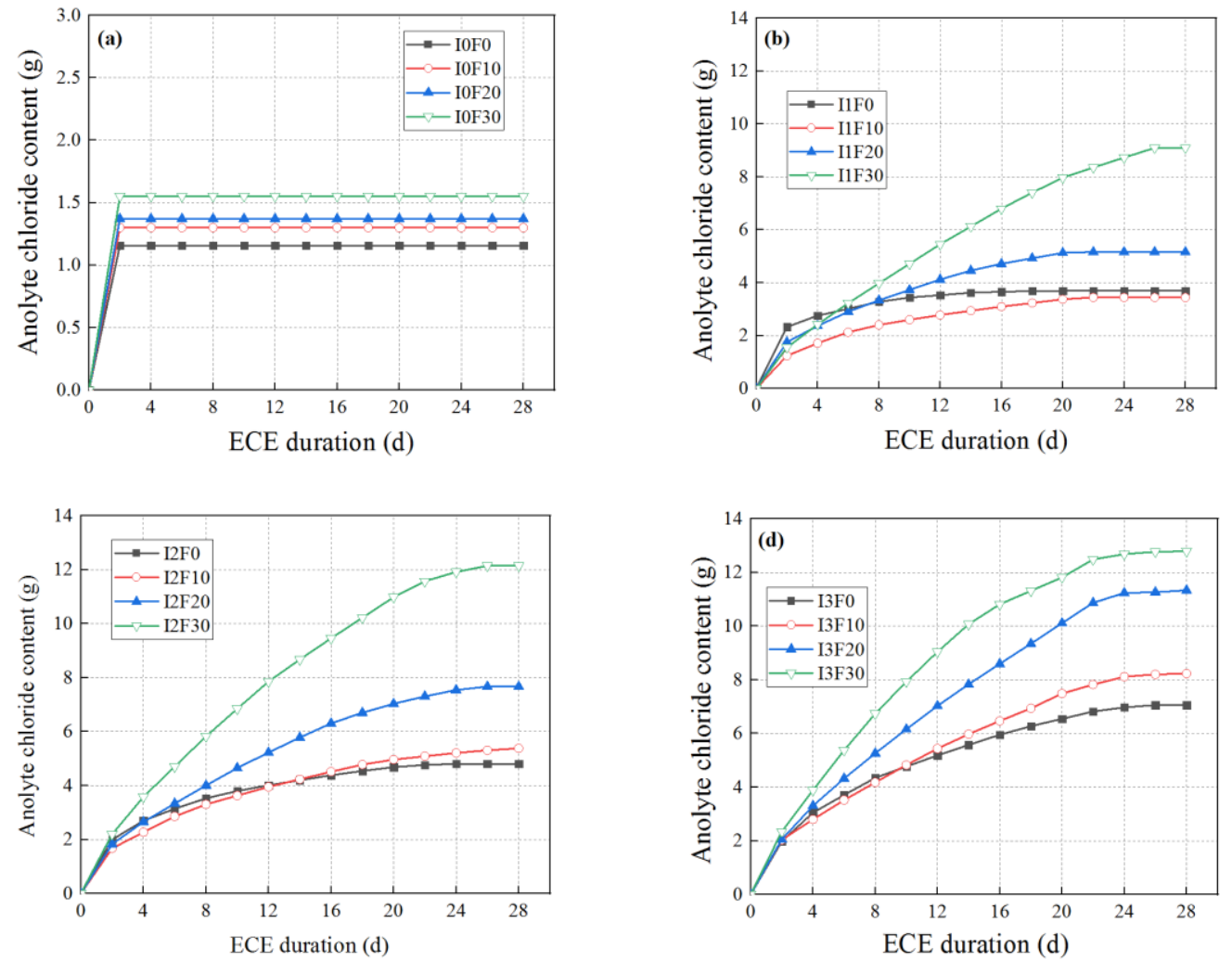

Fig. 7. Cumulative extracted chloride content changes with ECE time (present in the anolyte and measured by titrating the anolyte every $2 \mathrm{~d}$ ) for specimens treated with current densities of (a) 0 ; (b) $1 \mathrm{~A} / \mathrm{m}^{2}$; (c) $2 \mathrm{~A} / \mathrm{m}^{2}$; (d) $3 \mathrm{~A} / \mathrm{m}^{2}$

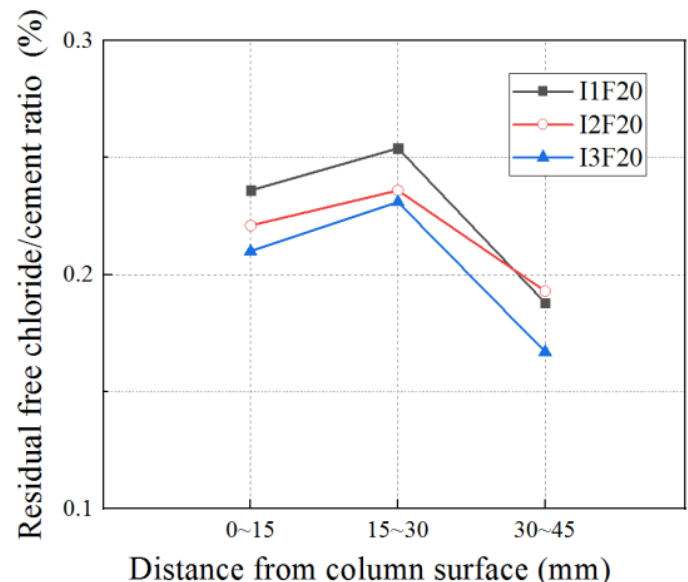

Fig. 8. Residual free chloride profile along the specimen depth 


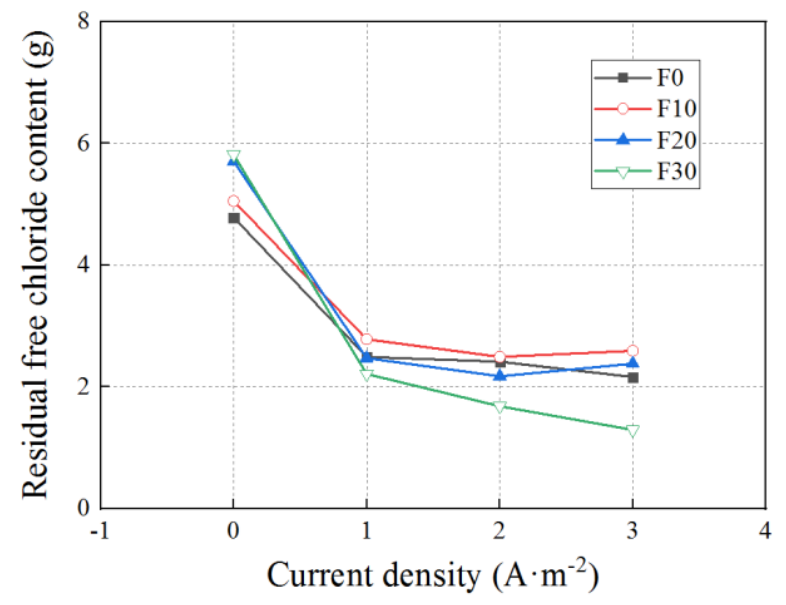

Fig. 9. Residual free chloride content in concrete after ECE treatment

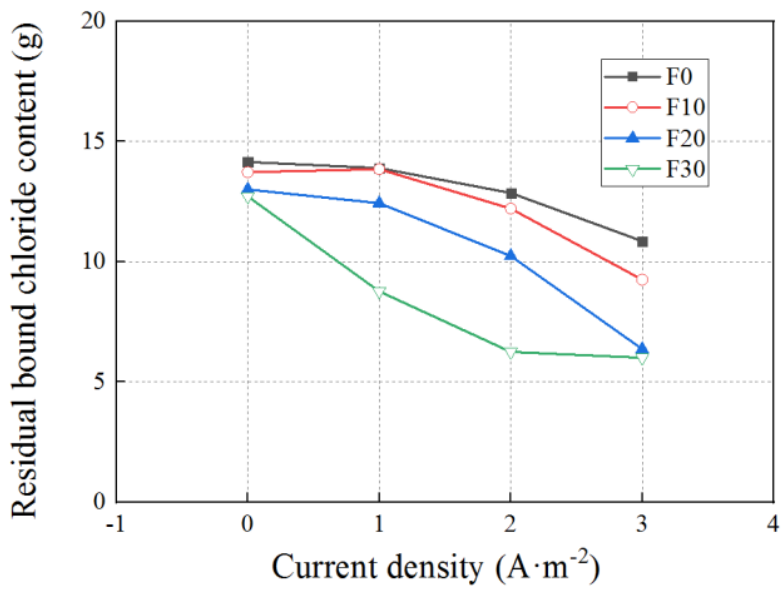

Fig. 10. Residual bound chloride content in concrete after ECE treatment 

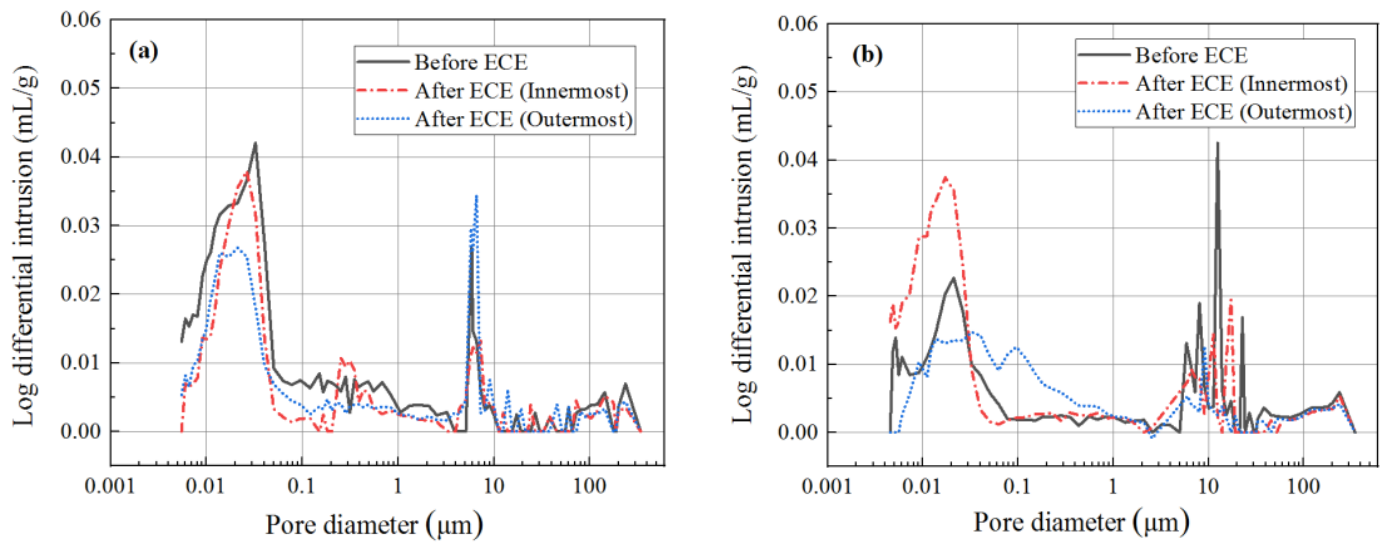

Fig. 11. Pore size distribution of concrete samples before and after ECE treatment:

(a) I2F0; (b) I2F30
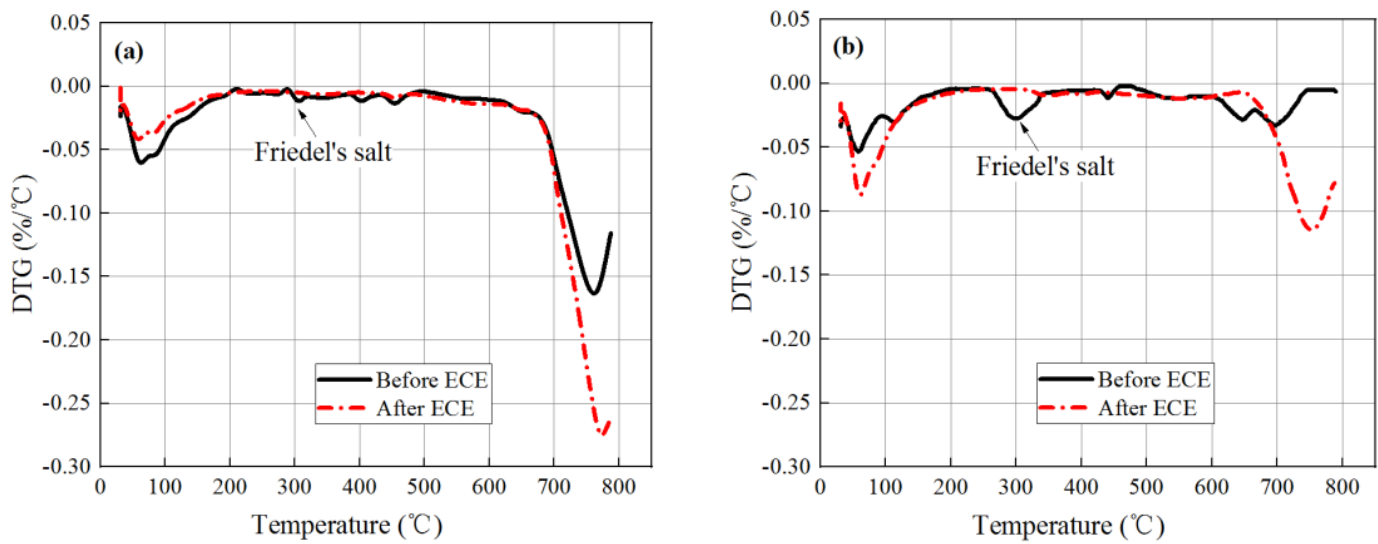

Fig. 12. DTG curves for concrete before and after ECE treatment with and without fly ash: (a) I2F0; (b) I2F30 
Tables

Table 1 Details of specimens

\begin{tabular}{cccc}
\hline Number & Current density & Replacement of fly ash & Anode \\
\hline I0F0 & 0 & 0 & $\mathrm{Cm}$ \\
I0F10 & 0 & 10 & $\mathrm{Cm}$ \\
I0F20 & 0 & 20 & $\mathrm{Cm}$ \\
I0F30 & 0 & 30 & $\mathrm{Cm}$ \\
I1F0 & 1 & 0 & $\mathrm{Cm}$ \\
I1F10 & 1 & 10 & $\mathrm{Cm}$ \\
I1F20 & 1 & 20 & $\mathrm{Cm}$ \\
I1F30 & 1 & 30 & $\mathrm{Cm}$ \\
I2F0 & 2 & 0 & $\mathrm{Cm}$ \\
I2F10 & 2 & 10 & $\mathrm{Cm}$ \\
I2F20 & 2 & 20 & $\mathrm{Cm}$ \\
I2F30 & 2 & 30 & $\mathrm{Cm}$ \\
I3F0 & 3 & 0 & $\mathrm{Cm}$ \\
I3F10 & 3 & 10 & $\mathrm{Cm}$ \\
I3F20 & 3 & 20 & $\mathrm{Cm}$ \\
I3F30 & 3 & 30 & $\mathrm{Cm}$ \\
\hline I2F0-Cs & 2 & 0 & $\mathrm{Cs}$ \\
I2F0-Cp & 2 & 0 & $\mathrm{Cp}$ \\
\hline
\end{tabular}

Table 2 Mix proportion of concrete $\left(\mathrm{kg} / \mathrm{m}^{3}\right)$

\begin{tabular}{cccccc}
\hline Cement & Fly ash & Water & Coarse aggregates & Sand & NaCl \\
\hline 400 & - & 200 & 1116 & 684 & 12 \\
360 & 40 & 200 & 1116 & 684 & 12 \\
320 & 80 & 200 & 1116 & 684 & 12 \\
280 & 120 & 200 & 1116 & 684 & 12 \\
\hline
\end{tabular}


Table $3\left[\mathrm{Cl}^{-}\right] /\left[\mathrm{OH}^{-}\right]$at different depths from concrete surface

\begin{tabular}{cccccccccc}
\hline & \multicolumn{7}{c}{ Depth $(\mathrm{mm})$} \\
\cline { 2 - 10 } Specimen & \multicolumn{7}{c}{$0 \sim 15$} & \multicolumn{7}{c}{$15 \sim 30$} & & $30 \sim 45$ & \\
\cline { 2 - 10 } & $n_{\mathrm{Cl}^{-} /}$ & $n_{\mathrm{OH}^{-} /}$ & {$\left[\mathrm{Cl}^{-}\right] /$} & $n_{\mathrm{Cl}^{-} /}$ & $n_{\mathrm{OH}^{-} /}$ & {$\left[\mathrm{Cl}^{-}\right] /$} & $n_{\mathrm{Cl}^{-} /}$ & $n_{\mathrm{OH}^{-} /}$ & {$\left[\mathrm{Cl}^{-}\right] /$} \\
I1F0 & 0.307 & 0.537 & 0.572 & 0.480 & 0.562 & 0.854 & 0.276 & 0.550 & 0.502 \\
I1F10 & 0.429 & 0.417 & 1.030 & 0.472 & 0.550 & 0.859 & 0.321 & 0.617 & 0.521 \\
I1F20 & 0.416 & 0.955 & 0.435 & 0.439 & 0.676 & 0.649 & 0.357 & 1.023 & 0.349 \\
I1F30 & 0.363 & 0.302 & 1.203 & 0.379 & 0.240 & 1.581 & 0.133 & 0.407 & 0.325 \\
I2F0 & 0.370 & 0.427 & 0.868 & 0.415 & 0.316 & 1.312 & 0.255 & 0.457 & 0.558 \\
I2F10 & 0.272 & 0.550 & 0.494 & 0.405 & 0.550 & 0.737 & 0.261 & 1.905 & 0.137 \\
I2F20 & 0.293 & 0.151 & 1.937 & 0.329 & 0.407 & 0.808 & 0.248 & 0.617 & 0.403 \\
I2F30 & 0.219 & 0.151 & 1.449 & 0.224 & 0.151 & 1.481 & 0.162 & 0.288 & 0.562 \\
I3F0 & 0.235 & 0.437 & 0.537 & 0.396 & 2.818 & 0.141 & 0.203 & 0.355 & 0.571 \\
I3F10 & 0.411 & 0.490 & 0.840 & 0.437 & 0.490 & 0.892 & 0.347 & 0.692 & 0.502 \\
I3F20 & 0.307 & 0.447 & 0.687 & 0.437 & 0.447 & 0.977 & 0.292 & 0.550 & 0.532 \\
I3F30 & 0.214 & 0.158 & 1.350 & 0.229 & 0.102 & 2.242 & 0.187 & 0.468 & 0.400 \\
I2F0-Cs & 0.347 & 1.514 & 0.229 & 0.416 & 0.813 & 0.512 & 0.342 & 0.661 & 0.517 \\
I2F0-Cp & 0.276 & 2.291 & 0.120 & 0.372 & 0.234 & 1.588 & 0.235 & 0.447 & 0.525 \\
\hline
\end{tabular}

Table 4 Pore size distribution of concrete specimens before and after ECE treatment

\begin{tabular}{lcccccc}
\hline \multirow{2}{*}{ Specimen } & Porosity & \multicolumn{4}{c}{ Pore size distribution (\%) } \\
\cline { 3 - 7 } & & $(\%)$ & $<20 \mathrm{~nm}$ & $20 \sim 60 \mathrm{~nm}$ & $60 \sim 300 \mathrm{~nm}$ & $>300 \mathrm{~nm}$ \\
\hline \multirow{2}{*}{ I2F0 } & Before ECE & 11.8 & 3.18 & 3.19 & 1.66 & 3.77 \\
& Innermost after ECE & 13.1 & 6.38 & 2.80 & 0.91 & 3.03 \\
& Outermost after ECE & 8.5 & 3.58 & 1.91 & 0.80 & 2.21 \\
\hline \multirow{2}{*}{ I2F30 } & Before ECE & 7.2 & 2.2 & 1.17 & 3.39 & 3.48 \\
& Innermost after ECE & 8.6 & 4.67 & 1.29 & 0.30 & 2.33 \\
& Outermost after ECE & 7.0 & 1.52 & 1.55 & 1.66 & 2.27 \\
\hline
\end{tabular}

